\title{
UNA EXPERIENCIA DE LA VIDA REAL
}

Maria Claudia Rodriguez*

El pasado 3 de marzo, cumplí 3 años de haber sufrido un Accidente Cerebro Vascular del hemisferio derecho, el médico que me recibió en urgencias de la Fundación Santa Fe, fue el doctor Enrique Jiménez Hakin; después de los primeros exámenes y de haber puesto al alcance toda la ciencia de la que se disponía en ese momento, se decidió tres días después, por la gravedad de mi estado operarme para extraer el coágulo porque no había sido absorbido por el mismo cerebro, la operación fue un éxito, teniendo en cuenta la magnitud del derrame.

Durante casi un mes, mi familia vivió un verdadero drama, mi esposo y nuestros tres hijos varones de 15, 12 y 10 años se sumieron en la tristeza y el desconcierto; siendo yo una devota del divino niño Jesús, mi familia se refugió en Él a quien le hicieron con mucha fe una novena. Los niños estaban muy angustiados, pues no sabían cuál iba a ser el desenlace de su mamá, si iba a morir o si iba a quedar completamente paralizada, no es motivo de este articulo pero su comportamiento hasta el día de hoy ha sido el de buenos hijos, me han apoyado mucho en mi recuperación, cuando he flaqueado, me animan, cada uno a su manera y su propio comportamiento.

Soy la hija mayor de una familia compuesta por mis padres y cinco hermanos, mi influencia dentro del contexto familiar había sido muy grande, razón por la cual mi accidente provocó un gran traumatismo, a tal punto que mi padre perdió 17 kilos de peso, esto no quiere decir que mi madre y mis hermanos no hubiesen sufrido de igual forma, pues mis dos hermanas que viven en el exterior viajaron para acompanarme en este difícil momento.

Por ejemplo, mi hermana Guiomar, es arquitecta, dejó sus obras y se dedicó a leer sobre mi caso, a aprender sobre lo que debía hacer conmigo y durante los primeros tres meses se dedicó a mí por completo. Me reforzaba la Terapia Física, me hacía

* Ingeniera de Sistemas. 
Terapia Cognoscitiva. Aún recuerdo los payasos que me dibujaba y me hacía colorear para buscar no ignorar el lado izquierdo; esto y otros ejercicios me realizaba día a día para lograr que yo atendiera el lado izquierdo y que me diera cuenta de lo que me rodeaba. Sin embargo, en este momento en ocasiones ignoro el lado izquierdo pero cada vez es menos; ésta es un área que no me trabajaron desde el punto de vista profesional, sólo lo que mi hermana me hacía.

Al permanecer sedada durante 25 días, los pulmones se llenaron de agua, tenía respirador $y$ cables por doquier, por lo cual tuvieron que hacer lo pertinente a mi situación, era un momento desalentador para cada una de las personas que estaban ligadas sentimentalmente a mí o mi familia. Hubo momentos tan difíciles que se llegó a dudar, si sobreviviría.

Los días transcurrieron y poco a poco fui saliendo de este estado, hasta estar completamente despierta, acto seguido tuve que enfrentar la triste realidad, estaba completamente paralizada de mi cuerpo izquierdo.

Dicen que las personas que sufren este tipo de accidentes pasan primero por una etapa de flacidez, realmente yo creo que éste no fue mi caso, pues desde que tuve total lucidez mi miembro superior izquierdo estaba completamente rígido y las férulas que pusieron para extender los dedos no sirvieron, casi todos los días me cambiaban de modelo, al punto que hoy tengo una colección de más o menos 15 férulas diferentes. Despues de haber permanecido 8 días sin sedantes me trasladaron a un cuarto, me realizaron otra serie de exámenes cognocitivos, para determinar que más se me habia dañado, lo único nuevo fue confirmar la pérdida del campo visual del ojo izquierdo.

En la medida que pasaban los días yo tomaba conciencia de la magnitud de lo que me había sucedido, la tristeza se apoderaba de mí y no lograba entender el por qué a mi???,... una mujer joven, que creía tener todo controlado y bien manejado, buena hija, con una linda familia, donde el amor era el eje central y en lo profesional, no podía estar mejor, un excelente puesto, ganado por méritos, mi carrera podía vislumbrarse con total éxito.

Bueno, una vez tuve que aceptar lo sucedido y entender que tenía que empezar una nueva etapa en mi vida, donde el mayor tiempo tendría que dedicarselo a la Terapias, tuve mucho miedo y angustia pero tenía que aceptarlo. En el Hospital los 
médicos tratantes me hablaron y programaron mis terapias tanto física como ocupacional. Todas las mañanas llegaba la fisioterapeuta sentia miedo y mucho dolor pues decian que mi hombro izquierdo estaba "congelado", por falta de movimiento, la Fisioterapeuta desde un comienzo fue muy dulce, pero a su vez firme, ella poco a poco y durante estos tres largos años ha logrado que hoy día camine, (si no como una reina, sí como una princesa), ha permanecido a mi lado y ha sido más que mi Terapeuta, mi amiga; cuando estoy triste me deja llorar y me consuela, sin antes poner lo que me entristece en la dimensión correcta.

Lo anterior no sucedió con la Terapeuta Ocupacional, de ello recuerdo que estando hospitalizada llegaba con una pila de conos, unos sobre otros, forrados de diferentes texturas, me sentaba frente a ellos y me decía "Extienda la mano y saque uno por uno" ¿cómo hacer esto? si no puedo mover el brazo y abrir la mano, era lo que yo con rabia me preguntaba en silencio día tras día al verla entrar; a medida que fue pasando el tiempo me sentía frustrada, más triste y desconcertada, solamente estaba segura de una cosa odiaba la terapia ocupacional y como reflejo a esto a las Terapeutas Ocupacionales, lo que sin duda ocasionó un gran retraso en mi evolución.

La empresa donde trabajaba me envió durante un tiempo a un Centro de Rehabilitación en los Estados Unidos, fueron dos meses de rehabilitación permanente, la gran meta de este hospital era convertirme en una persona autosuficiente; el rechazo hacia la Terapia Ocupacional continuó y, por lo tanto, el progreso del miembro superior izquierdo no fue tanto como el que yo esperaba, claro que al final del tratamiento se había logrado que fuera independiente, se había alcanzado la meta propuesta.

A mi regreso cambié de Fisiatra y de Terapeuta Ocupacional, probé varias profesionales, pero el rechazo y frustración con mi mano izquierda seguian iguales, por fin conocí a mi actual Terapeuta Ocupacional con quien he logrado vencer el rechazo que sentía hacia mi mano, ella con mucha paciencia y entendiendo mi frustración, ha logrado grandes progresos en mi brazo y mi mano, actualmente la siento menos espástica y la meta es lograr para el final de año que la mano abra, coja un vaso con agua y lo lleve a mi boca sin derramarlo. En este momento he logrado que la mano responda cogiendo objetos de diferentes formas, soltarlas con mayor precisión e involucrarla en algunas actividades de la vida diaria, esto me hace sentir contenta y satisfecha. 
Poco a poco he ido entendiendo para qué me sirve la Terapia Ocupacional, por qué me trabajan así y qué puedo lograr hacer, de las cosas que más me gustan de las sesiones tanto de Terapia Física como ocupacional es que se inician a partir de lo que hice la última vez que estuvimos trabajando y esto es tan importante para mí que incrementa la motivación.

Quiero terminar este artículo diciéndoles a todós los profesionales que trabajan en la recuperación de personas discapacitadas como yo que somos personas muy suceptibles, lo cual nos hace difíciles de manejar y llevar, pero que el éxito se obtiene en tratarnos como seres humanos.

Agradezco la recuperación hasta hoy obtenida, a Dios, al trabajo y apoyo de mis padres, hermanos, mi esposo y mis hijos.

En el campo Profesional quiero agradecer al neurólogo, doctor Enrique Jiménez, al Fisiatra doctor Juan Pablo Forero, Mi Fisioterapeuta Lucía Arcila y mi actual Terapeuta Ocupacional. 